University of Nebraska - Lincoln

DigitalCommons@University of Nebraska - Lincoln

Timothy J. Gay Publications

Research Papers in Physics and Astronomy

September 1994

\title{
Clean ultrahigh vacuum system with single-structure diffusion pumps
}

Timothy J. Gay

University of Nebraska - Lincoln, tgay1@unl.edu

M.C. Fritts

University of Missouri-Rolla, Rolla, Missouri

J.E. Furst

University of Missouri-Rolla, Rolla, Missouri

M.A. Khakoo

University of Missouri-Rolla, Rolla, Missouri

E.R. Mell

University of Missouri-Rolla, Rolla, Missouri

See next page for additional authors

Follow this and additional works at: https://digitalcommons.unl.edu/physicsgay

Part of the Physics Commons

Gay, Timothy J. ; Fritts, M.C.; Furst, J.E.; Khakoo, M.A.; Mell, E.R.; Seiger, M.T.; and Wijayaratna, M.W.K.P., "Clean ultrahigh vacuum system with single-structure diffusion pumps" (1994). Timothy J. Gay Publications. 2.

https://digitalcommons.unl.edu/physicsgay/2

This Article is brought to you for free and open access by the Research Papers in Physics and Astronomy at DigitalCommons@University of Nebraska - Lincoln. It has been accepted for inclusion in Timothy J. Gay Publications by an authorized administrator of DigitalCommons@University of Nebraska - Lincoln. 


\section{Authors}

Timothy J. Gay, M.C. Fritts, J.E. Furst, M.A. Khakoo, E.R. Mell, M.T. Seiger, and M.W.K.P. Wijayaratna 


\title{
Clean ultrahigh vacuum system with single-structure diffusion pumps
}

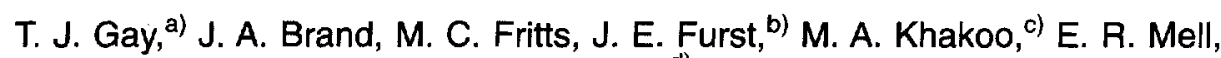 \\ M. T. Sieger, and W. M. K. P. Wijayaratna ${ }^{\text {d) }}$ \\ Laboratory for Atomic and Molecular Research and the Physics Department, University of Missouri-Rolla, \\ Rolla, Missouri 65401
}

(Received 12 July 1993; accepted 9 April 1994)

\begin{abstract}
A practical example of the use of single-structure diffusion pumping groups in an experiment requiring hydrocarbon-free, ultrahigh vacuum is presented. With the use of proper vacuum procedures and careful foreline design and operation, but with no exotic hardware or liquid nitrogen, we have demonstrated that such a pump could provide vacuum that was "clean," i.e., which had no residual pump-oil contamination to a partial pressure below $10^{-8} \mathrm{mbar}$. Their use is thus compatible, at least in peripheral vacuum chambers, with standard "UHV-surface science" processes. We discuss our vacuum system in detail, and present a review of the literature on the production of clean vacua with diffusion pumps.
\end{abstract}

\section{INTRODUCTION}

We have developed recently in our laboratory an apparatus to study the scattering of polarized electrons by effusive, high-density noble-gas targets. The system, shown schematically in Fig. 1, consists of a GaAs-photoemission polarizedelectron source, a Mott electron polarimeter, and a target chamber. ${ }^{1,2}$ While photoemission from GaAs has many advantages as a source of polarized electrons, it also has one significant drawback: its stringent requirement of an ultrahigh vacuum environment essentially free of organic contaminants and carbon monoxide. ${ }^{3,4}$ Our experiments, on the other hand, introduced the contrasting vacuum requirement of sustained, high-throughput pumping of noble gases at elevated pressures, which essentially dictated the use of large diffusion or turbomolecular pumps on the target chamber. The simultaneous fulfillment of these two diverse requirements called for a very clean target vacuum system ("clean" in this context being defined as a lack of $\mathrm{CO}$ and hydrocarbons), and effective isolation of the GaAs source from any residual contamination introduced by the target pumps.

Sputter-ion pumps in a noble-gas-pumping differential configuration were chosen initially to provide absolutely clean pumping of the GaAs source (Perkin Elmer DI 200 $\ell / \mathrm{s}$ ) and the adjacent Mott polarimeter (Perkin Elmer DI 120 $\ell / \mathrm{s})$. These chambers are devoid of organic vacuum materials. The Mott polarimeter is ideally suited as a differential pumping chamber between the electron source and target, having small entrance and exit apertures and no unobstructed line-of-sight between them. ${ }^{2}$ Thus it was expected that the partial pressure of contaminants due either to pump backstreaming or the presence of elastomer seals in the target region would be reduced by an amount of order $10^{4}$, the ratio

\footnotetext{
a) Author to whom correspondence should be addressed. Current address: Behlen Laboratory, University of Nebraska, Lincoln, NE 68588-0111.

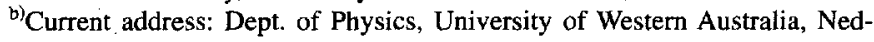
lands, Western Australia.

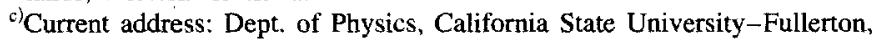
Fullerton, CA 92634.

${ }^{d)}$ Current address: Dept. of Physics, University of Colombo, Colombo 03, Sri Lanka.
}

of the Mott pump entrance area to the area of the Mott entrance aperture.

The major remaining concern was to develop the cleanest possible pumping system for the target chamber. Our initial deliberations were influenced by a prejudice, apparently shared by a majority of experimental physicists, that turbomolecular pumps are "cleaner" than diffusion pumps, and that unless extraordinary measures involving extensive liquid nitrogen trapping are taken with a diffusion-pumped system, backstreaming of the diffusion pump oil will inevitably result in gross contamination of the vacuum. We thus first considered pumping systems using turbopumps with grease or oillubricated bearings, or diffusion pumps with large, elaborate "UHV" liquid nitrogen traps, such as the Vacuum Generators VGZ series. (Magnetically levitated turbopumps were considered to be too expensive.)

A subsequent review of the vacuum literature, however, revealed a number of useful facts, which we summarize here. $^{5-26}$

(1) Modern diffusion pumps, with fractionating boilers, ejection stages, and properly designed caps or baffles atop their pumping stacks, have essentially zero backstreaming rate when in operation. The partial pressure of the pumping fluid above the pump is effectively associated with its vapor pressure at the temperature of the uppermost component in the pump, be it stack cap, baffle, or trap. ${ }^{9,14,15,18-20,22,25,26}$ At liquid nitrogen temperatures, the extrapolated vapor pressure of perfluoropolyether fluid, e.g., Santovac 5, is less than $10^{-30}$ mbar. $^{27}$

(2) Even modern diffusion pumps will exhibit substantial backstreaming in certain pressure regimes which occur most typically during start-up and shut-down procedures. $^{5-7,12,13,15-17,23}$ Particular care must thus be exercised when carrying out these operations.

(3) In vacuum systems employing oil-lubricated roughing and/or forepumps, the major system contamination often comes from these components, as opposed to the highvacuum pumps. ${ }^{7,8,11-13,17,19,21-26}$ Such contamination can be eliminated only by proper design of the fore and roughing lines and again, by careful attention to the operational procedures used with the system. 


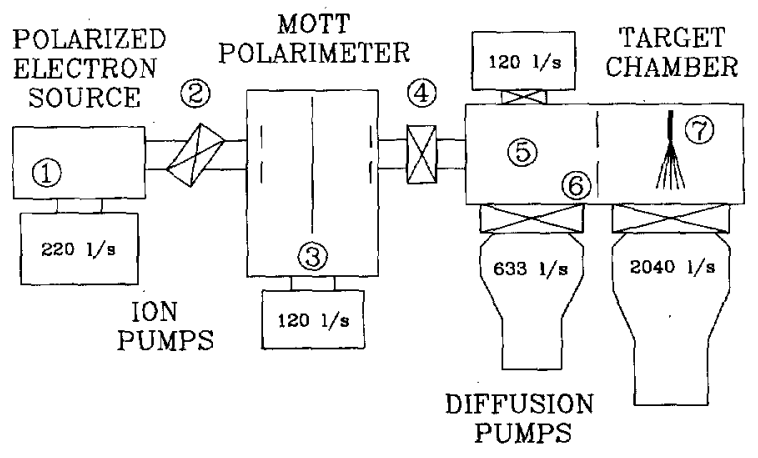

FIG. 1. Schematic view of vacuum system showing elements relevant to the text: (1) RGA in source; (2) manual bakeable in-line copper-sealed valve; (3) collimators and baffles which aid in differential pumping of the Mott polarimeter; (4) electropneumatic viton-sealed gate valve; (5) target RGA; (6) target-gas containment baffle; (7) effusive gas target. A $120 \mathscr{\ell} / \mathrm{s}$ ion pump on top of the target chamber is used to maintain vacuum when the diffusion pump butterfly valves are closed.

(4) When proper vacuum procedures are followed, "single-structure" diffusion pumps, with a large, watercooled top stack element and an integral butterfly valve [variations on this design are sold by Edwards ("Diffstack"), Alcatel ("Crystal"), and Balzers ("Diffset")], have been shown to produce vacua as free or freer of hydrocarbons and CO than those produced with conventional (hydrocarbonlubricated) turbopumps ${ }^{18-20,22}$ even when no high-vacuum cold trap was used.

In light of the above points, we have summarized in Table I some of the main advantages and disadvantages of conventional turbopumps and single-structure diffusion pumps that are particularly relevant for our application. Cost was also a major issue in our analysis. The target gas load and maximum pressure requirements in our experiments suggested the use of one $2500 \mathrm{f} / \mathrm{s}$ and one $1000 \ell / \mathrm{s}$ pump. A cost estimate (made in 1988) for the appropriate turbopumps fitted with gate valves was $\$ 48000$. Single-structure diffusion pumps

TABLE I. Comparison of diffusion and hydrocarbon-lubricated turbomolecular pumps.

\begin{tabular}{|c|c|}
\hline Turbomolecular pump & Diffusion pump \\
\hline $\begin{array}{l}\text { Advantages: } \\
\text { (1) Relativity immune to } \\
\text { procedural errors resulting } \\
\text { in contamination } \\
\text { (2) Good rejection of foreline } \\
\text { contaminants } \\
\text { (3) No need for cold trap }\end{array}$ & $\begin{array}{l}\text { Advantages: } \\
\text { (1) Low cost } \\
\text { (2) Low maintenance } \\
\text { (3) As clean or cleaner than } \\
\text { conventional turbopumps }\end{array}$ \\
\hline $\begin{array}{l}\text { Disadvantages: } \\
\text { (1) Potential for catastrophic } \\
\text { damage (rotor blades or } \\
\text { bearings) } \\
\text { (2) Regular costly maintenance } \\
\text { (3) Poor compression ratio for } \\
\text { light gases }\end{array}$ & $\begin{array}{l}\text { Disadvantages: } \\
\text { (1) Potential for massive, } \\
\text { macroscopic contamination } \\
\text { (2) Light hydrocarbon fractions } \\
\text { from foreline can migrate } \\
\text { through boiler and backstream } \\
\text { during operation } \\
\text { (3) Backstreaming can occur at } \\
\text { transition pressures during } \\
\text { start/stop }\end{array}$ \\
\hline
\end{tabular}

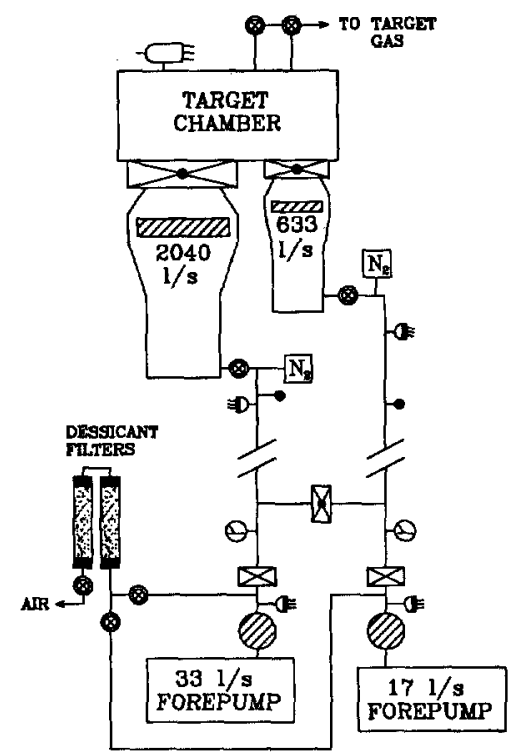

\begin{tabular}{|c|c|c|c|}
\hline \multicolumn{4}{|c|}{ TARGET VACUUM SYSTEM } \\
\hline 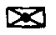 & MANUAL GATE VALVE & (2) & BLECTROPNEUMATIC VALVE \\
\hline 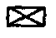 & EIECTROPNEUUATIC GATE VALVE & $\underline{\mathbf{N}_{3}}$ & DRY-NITROGEN PURGE NLET \\
\hline $\mathbb{Z Z}$ & COLD TRAP & $-\theta$ & BOURDON GAUGE \\
\hline$\theta$ & BAKRABLE YOLECULAR SIEVE TRAP & & LAB FOOR / BASEMONT CERING \\
\hline$\rightarrow$ & LEAK-CHECK ACCESS PORT & & \\
\hline$\Rightarrow D-$ & THERMOCOUPLE GAUGE TUBE & & BAYARD-ALPERT GAUGE TUBE \\
\hline
\end{tabular}

FIG. 2. Target chamber vacuum system showing details of foreline.

with integral cryoplates and manual butterfly valves cost $\$ 22000$, while less expensive diffusion pumps fitted with UHV cryotraps and in-line valves (which provide the cleanest pumping of the three alternatives) were $\$ 64000$ for the requisite pumping speed. Given these options, we chose to use single-structure diffusion pumps. We did not feel that the cost of the UHV cryotrap option was justified by its marginal improvement in cleanliness, and the single-structure diffusion pumps appeared to be a better choice than turbopumps.

The purpose of this article is to present, in some detail, a vacuum system that has worked well for our application. While the quantitative performance of single-structure diffusion-pumping systems has been discussed in the literature, ${ }^{18-20,22,28}$ we are unaware of any detailed reports on their application in a working system, and specifically in a scientific research apparatus requiring UHV surfacecleanliness conditions. An ancillary goal of this article is to combine in one place a variety of useful facts we have gleaned from the vacuum literature that have been incorporated successfully in our system, and which we feel would be of interest to physical scientists who use high- and ultrahigh vacuum systems.

\section{TARGET VACUUM SYSTEM}

In this section, we describe the target vacuum apparatus, shown in Fig. 2, keeping in mind that one of its principal design requirements (and the one of central importance to this report) was that it introduce minimal hydrocarbon and 
$\mathrm{CO}$ contamination to the remainder of the experiment's vacuum system. The target vacuum chamber is essentially a $20 \mathrm{~cm}$ diameter, $75 \mathrm{~cm}$ long tube of stainless steel, closed by a variety of Conflat and Ultratorr flanges and fittings. This tube is pumped at one end by an Edwards Diffstack (CR250M), with a nominal air pumping speed of $2040 \ell / \mathrm{s}$, directly under the effusive gas target. A second smaller unit (CR160M; $633 \ell / \mathrm{s}$ airspeed) is placed at the tube's other end, and provides a degree of differential pumping between the gas target and the adjacent Mott polarimeter, in that the target vacuum chamber is divided in half by a baffle installed to partially contain stray target gas.

The diffusion pump forelines are made of $7.6 \mathrm{~cm}$ diameter copper tube and extend about $20 \mathrm{~m}$ to a basement room directly under our lab. Two Sargeant-Welch belt-drive twostage vane pumps evacuate the forelines. A $33 \ell / \mathrm{s}$ pump (model \#1398H) is used for the large diffusion pump line, and a $17 \ell / \mathrm{s}$ pump (\#1375) is used on the smaller foreline. These forepumps are larger than necessary for our gas loads, but were available at no cost when the system was constructed. There are no separate roughing lines on the system. $^{13}$

\section{A. Diffusion pumps and cryotraps}

The single-structure diffusion pumps were chosen for the reasons mentioned in Sec. I. Their size was dictated by our gas loads and the maximum allowable pressures in the target region. The performance of these pumps has been documented in the literature. ${ }^{18-20,22,28}$ The most important aspect of their performance from our point of view is their extremely low backstreaming rate. The single-structure configuration with no cryotrap or integral valve has a backstreaming rate at the inlet port of less than $10^{-8} \mathrm{mg} \mathrm{cm}^{-2} \mathrm{~s}^{-1}$ when Santovac-5 is used as the pumping fluid. This corresponds to the extrapolated evaporation rate of the fluid at $0{ }^{\circ} \mathrm{C}^{27}$ In addition to its superior vacuum properties, Santovac-5 forms a conducting layer when cracked on electron optical elements and is relatively easy to remove from a system by baking. ${ }^{13,20,27,28}$ To lower further the backstreaming rate of the Santovac as well as any residual light oil fractions from the pump's boiler or the foreline, we chose to use diffusion pumps with integral chilled baffles. These baffles, which are placed directly above the cold cap at the top of the pumping stack, serve both to reduce the vapor pressure of any oil at the entrance to the pump and to remove line-of-sight paths between the relatively warm lower pump walls and the pump entrance.

The manufacturer sells the cryotrap option not as an antibackstreaming measure but as a way to increase the water vapor pumping speed for applications in which fast turnaround is important. Consequently, the cryobaffle is supplied with a liquid nitrogen cryostat. Since we were only interested in reducing oil vapor pressure, we decided that chilled methanol would be adequate as a cryogenic fluid. The entrance and vent ports of the two cryostats were thus connected in parallel to a recirculating methanol chiller (FTS model RC-200-80C) with an output temperature of $-75^{\circ} \mathrm{C}$. The transfer lines were made from $3 / 8$ in i.d. Tygon tubing and were all shorter than $3 \mathrm{~m}$. They were insulated with foam-rubber tubes. It is possible that a less expensive methanol or ethylene glycol system operating at temperatures in the range between 0 and $-40^{\circ} \mathrm{C}$, or even chilled water, would have been adequate for our needs. ${ }^{29}$

We did not buy electropneumatic actuators for the highvacuum butterfly valves because of several reports in the literature that rapid opening of these valves could result in substantial bursts of oil into the main vacuum system. ${ }^{22,23}$ Such bursts are especially intense at just the pressures where high vacuum valves are most often opened: in the $10^{-3}-10^{-4}$ mbar range..$^{5,13,17,23}$ The disadvantage of manual valve control is that the target chamber cannot be isolated from the diffusion pumps automatically. This has not proved to be a serious problem in our system. We have subsequently learned that air throttling systems are available which allow the butterfly valve to be opened or closed automatically with arbitrary speed.

\section{B. Foreline and purge system}

The foreline and purge systems are shown schematically in Figs. 2 and 3, respectively. Each foreline is isolated by an electropneumatic right-angle valve from the diffusion pump it backs. Immediately below this isolation valve on each line is a thermocouple gauge and a dry-nitrogen-purge inlet. The main forelines descend about $20 \mathrm{~m}$ into the basement below our lab, where they connect to electropneumatically operated forepump isolation gate valves. Between these isolation valves and the pumps are bakeable molecular sieve traps, connected to the pumps via bellows vibration isolators. An up-to-air line also enters the system just above the traps. This line bleeds dry air into the forepump when it is shut off, to prevent possible "suck-back" of pump oil.

A number of authors have noted that serious contamination can result from improper design and/or operation of fore-vacuum and roughing lines. $7,8,11-13,17,19,21-26$ In particular, the advantages of a foreline purge in combination with the use of single-structure diffusion pumps have been documented by Dennis et al. ${ }^{22}$ In order to minimize forepump oil contamination of our target, we have incorporated the following features in the forelines.

(1) Purging with dry nitrogen. Maintaining a controlled leak of dry purge gas into the foreline under viscous flow conditions has been recommended by several authors. ${ }^{12,13,17,22,24}$ The purge gas molecules act to "beat back" forepump oil vapor both in the volume and on the walls of the foreline. This action is particularly advantageous in reducing light oil fractions that result from the breakup of forepump oil by heat and friction in the pump itself. If not stopped in the foreline, these fractions can migrate through the diffusion pump boiler and find their way into the high vacuum system.

Following the discussions of Holland, ${ }^{12}$ Lewin, $^{24}$ and Jones and Tsonis, ${ }^{7}$ our purge pressure is maintained at 0.1 mbar to ensure viscous flow conditions. The purge line enters the foreline just below the diffusion pump isolation valve. ${ }^{12}$ We use standard dry nitrogen which passes through a desiccant and particle filter before it enters the system via a bellows-sealed needle valve. It is probable that a simple air leak passed through a long column of desiccant such as Dr- 


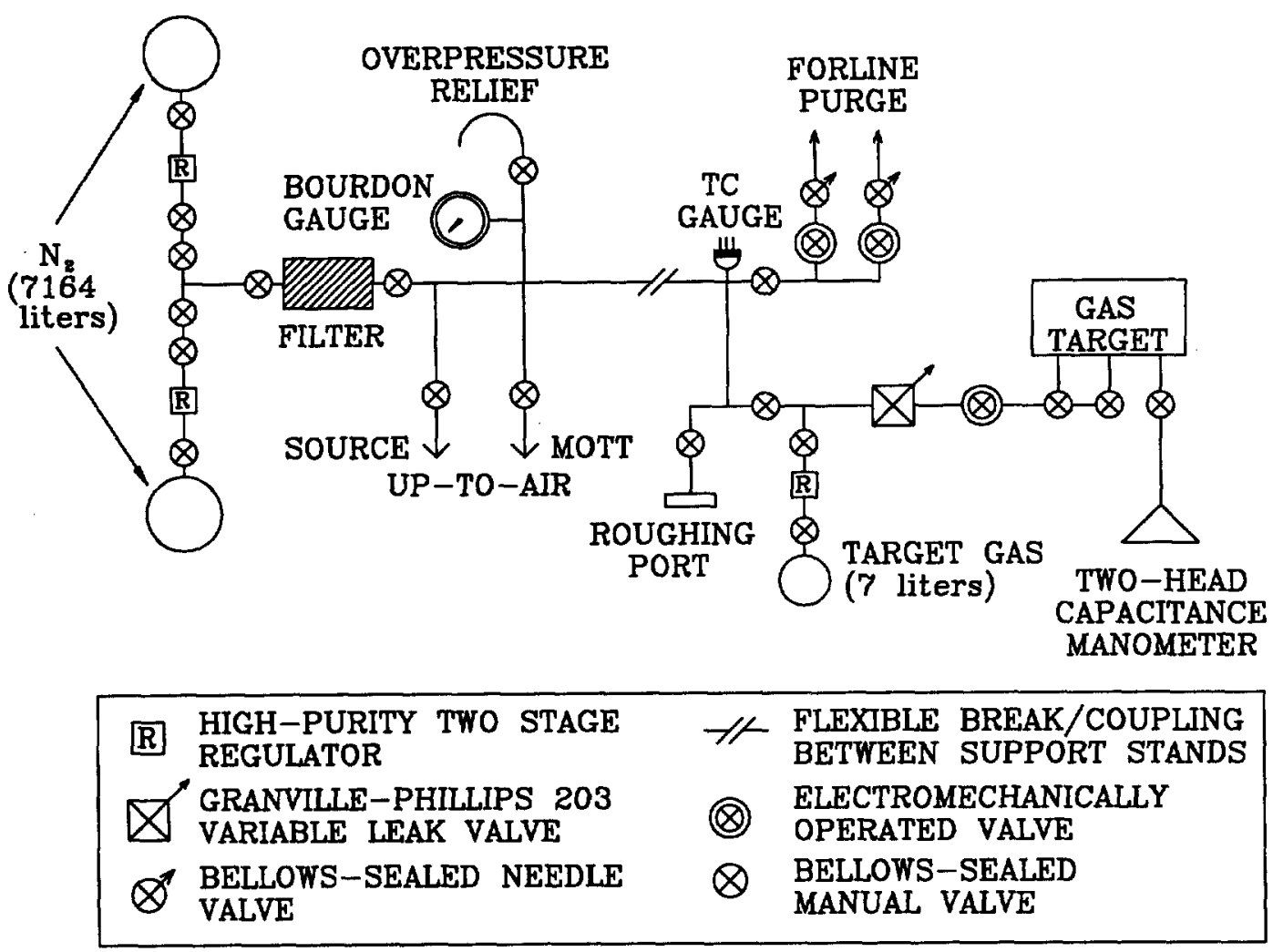

FIG. 3. Target/purge gas handling system.

irite, dessicated liquid nitrogen boil-off, or a clean dry source of compressed air would be acceptable sources of purge gas. The purge line also connects directly to the target chamber. A number of reports have emphasized the utility of a viscous flow purge in cleaning badly contaminated high vacuum chambers, ${ }^{7}$ and in maintaining a purge from above the diffusion pump until its vapor jet has been established during a start-up sequence. ${ }^{12,13,15,17}$ We have not used a target purge in our system to date.

(2) Long forelines. In concert with the nitrogen purge, isolation between the forepump and diffusion pump is maintained by the sheer length of the forelines. ${ }^{12}$ The generally accepted maxim that forelines should be short and fat (i.e., have maximum conductance) is true only when the vacuum system is throughput-limited. From the viewpoint of elimination of foreline vapor, practically the opposite rule is correct: the foreline should have the minimum conductance which, in combination with the forepump's speed, is consistent with the gas loads that will be encountered. ${ }^{8}$ In our system, we need an effective pumping speed of about $1 \mathrm{l} / \mathrm{s}$ at the top of the large diffusion pump foreline to ensure that the diffusion pump's maximum tolerable forepressure is not exceeded under maximum gas load. The actual pumping speed of this line is roughly $2 \ell / \mathrm{s}$, determined almost exclusively by the line conductance; the mechanical pump has a rated speed of $33 \ell / \mathrm{s}$. Our forelines are about $20 \mathrm{~m}$ long and 7.6 $\mathrm{cm}$ in diameter. While shorter, narrower lines would have equivalent pumping characteristics and would reduce expense, longer lines have the advantage of reducing contami- nation due to surface diffusion (acting essentially as anticreep barriers) and allow the physical isolation of the large, noisy forepumps.

(3) Bakeable molecular sieve traps. Zeolite is effective in removing backstreaming forepump oil. ${ }^{8}$ Indeed, zeolite traps can have a higher pumping speed for light hydrocarbon fractions than does the forepump itself. ${ }^{21}$ We use large $(7.9 \mathrm{~cm})$ entrance and exit-aperture traps (MDC model MST-300-2) which are bakeable in situ and can be recharged. The traps are baked with the Diffstack isolation valves closed but with the purge turned on. The traps must be baked every few weeks and the sieve replaced every few months for optimum performance..$^{20}$ We considered both liquid nitrogen and Micromaze ${ }^{30}$ traps as alternatives to zeolite. Micromaze traps were attractive but were available only in sizes that would have unduly restricted the foreline conductance. The cost of operating liquid nitrogen traps, especially in conjunction with a viscous-flow purge, outweighed their desirability from the standpoint of cleanliness.

(4) Use of diffusion pump oil in the forepumps. A number of investigators have reported the use of diffusion pump oil (e.g., DC705 or Convoil 20) in their forepumps as a means of reducing the vapor pressure of light hydrocarbon fractions, and hence backstreaming of the pump fluid. ${ }^{8,13,26} \mathrm{Ig}$ noring dire warnings in the forepump operator's manuals against using anything other than Duoseal oil, ${ }^{31}$ we flushed and filled our pumps with Diffoil 20, a high-grade petroleum-based $\mathrm{oil}^{30}$ with a vapor pressure of $10^{-7} \mathrm{mbar}$ 
TABLE II. Computer-controlled vacuum safety interlock system.

\begin{tabular}{ll}
\hline Parameters monitored & \multicolumn{1}{c}{ Components controlled } \\
\hline (1) Target chamber pressure & (1) Diffusion pump power \\
(ionization gauge) & (2) Diffusion pump isolation valves \\
(2) Foreline pressure & (3) Foreline purge shutoff valves \\
(thermocouple gauges) & (4) Forepump gate valves \\
(3) Diffusion pump cooling- & (5) Foreline up-to-air valves \\
water flow & (6) Forepump power \\
(4) Diffusion pump cooling- & (7) Target chamber/Mott \\
water temperature & (8) Alarm light and horn \\
\hline
\end{tabular}

(Duoseal's vapor pressure is $10^{-3} \mathrm{mbar}$ ). Despite some viscosity difference between the two oils, our forepumps seemed to work well over a period of about six months. After six months of operation, during which the Diffoil was replaced on several occasions, a number of mechanical pump failures occurred including, in one case, the freezing of vanes in their rotor. These problems, in conjunction with our growing realization that breakdown of forepump oil due to heat and friction inevitably produces high-vapor-pressure fractions in any case, ${ }^{12,18}$ led us to switch back to Duoseal. No change in any system parameters was observed.

It is our conclusion, based upon working experience with this system, that these four features represent some degree of redundancy from the standpoint of minimizing foreline contamination. Certainly the use of diffusion pump oil in the forepump appears to have been unnecessary, if not undesirable. It is our opinion that the purge and long forelines are necessary for long-term cleanliness, while the zeolite traps serve as a first defense against gross contamination. The latter was visually evident when the traps were removed to change their sieve charge; no oil was observed in the forelines above the trap bodies, but it had pooled in the lines between the traps and forepumps. The zeolite traps are particularly important in anomalous operating situations, e.g., when the source of purge gas accidentally runs out (see below).

\section{Safety interlock}

In order to minimize the consequences of vacuum component failure, a computer-controlled safety interlock was developed to monitor the experiment. A good interlock system significantly reduces the possibility of gross, catastrophic contamination (e.g., Santovac dripping from the residual gas analyzer head) by the diffusion pumps or their forelines, thereby removing one of the disadvantages of diffusion pump versus turbopump operation. Table II lists the system parameters which are monitored and controlled. All monitored parameters except water flow have set points for initiation of a programmed response by the interlock computer. These setpoints can be changed from the system's keyboard. The target and foreline pressures are monitored by a Bayard-Alpert gauge and thermocouple gauges, respectively. Both high and low setpoints are used for foreline pressure. Thus either a foreline leak or a failure of purge gas flow would cause the interlock to act. Cooling water flow to each pump system is monitored by paddle-wheel switches (Pro- teus model 100). These devices have been found to be reliable, whereas various other paddle-wheel flow tranducers we tried were not. The water temperature is measured with an immersable thermocouple probe. This latter parameter is important because we use a closed recirculating water system for the diffusion pumps.

As an example of how the interlock might divert disaster, consider the sudden opening of a small leak in the foreline. This would cause the foreline pressure to exceed the "high" setpoint. The computer would execute, within $0.1 \mathrm{~s}$, in order the following sequential actions: close the isolation valve between the target chamber and the Mott polarimeter, close the diffusion pump isolation foreline valve, close the forepump isolation gate valve, turn off the diffusion pump, stop the foreline purge, open the up-to-air valves on both sides of the desiccant column, and turn off the forepump. An alarm is then activated and the computer monitor indicates the setpoint that initiated the action and the times and a list of procedures carried out.

If the foreline pressure were to be reduced, indicating a failure of the purge gas, the alarm would be activated but no other action taken other than the closing of the Mott isolation valve, on the assumption that the zeolite traps would prevent backstreaming temporarily. If no external action were taken within $6 \mathrm{~h}$, the computer would shut the system down. Failure of diffusion pump cooling water would cause the Mott isolation valve to be closed and the pump to be switched off, but the foreline would remain open and pumping.

The advantage of a computer-based interlock system, after the initial cost of design and setup have been paid, is that of flexibility and intelligence. System parameters are easily changed, and the status of the vacuum system can be easily monitored by an operator from the information displayed on the computer screen. In principle, we could have designed our interlock program to have more of a "big brother" mentality. For example, it could have been made to shut down the system if regular maintenance of the zeolite traps was not performed. Such sophistication required more development than we were willing to invest under the circumstances.

\section{Operation notes}

Operational procedures are as critical to the maintenance of clean vacua as proper hardware. In standard diffusionpumped vacuum systems, two routinely occurring situations can cause significant system contamination. ${ }^{5-7.12,13,15-17,23}$

(1) If the forepump is used to rough out the high vacuum chamber, and the roughing line is connected to this chamber for long periods of time at its ultimate pressure ( $\sim 5 \times 10^{-3}$ mbar), backstreaming from the roughing pump will be substantial unless the line is adequately trapped or purged.

(2) As the diffusion pump brings the main chamber from rough to high vacuum, enhanced backstreaming from this pump occurs in the "transition" region from viscous to molecular flow when the pump's top jets are not operating fully due to overload conditions. The effect on backstreaming of these two situations is shown schematically in Fig. 4. 


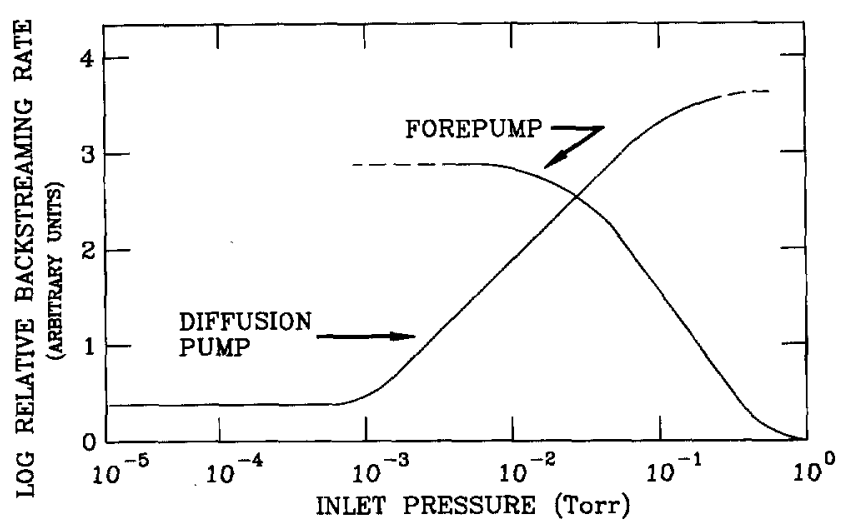

Fig. 4. Mechanical forepump and diffusion pump backstreaming rates vs their respective inlet pressures (see the text). After Fig. 10.2, Ref. 5; see also Ref. 16.

While the details of the curve in Fig. 4 vary from system to system (and depend particularly, from the low pressure side, on the diffusion pump trap and stack geometry), ${ }^{7}$ two important operating principles are apparent. First, main chamber roughing must occur in a clean manner; mechanical roughing pumps should never be connected to the main chamber under conditions of molecular flow. Second, the system must be brought through the transition region quickly when the high-vacuum valve is opened. It is also important, as noted earlier, that the high vacuum valve be opened slowly, to prevent a pressure burst from sweeping oil up from the diffusion pump into the main chamber.

To minimize backstreaming of the kind just discussed, we followed a standard start-up and shut-down procedure rigorously. The complete cycle is as follows (we assume that all the system components are at atmospheric pressure initially). The molecular sieve was first regenerated by baking with the foreline purge on, the diffusion pump isolation valve closed, and the forepump turned on with its gate valve open. When the foreline pressure is no longer elevated due to the zeolite bake, the trap heaters were turned off and the traps allowed to cool. The diffusion pump isolation valve was then opened (the high-vacuum butterfly valve was already open) causing the diffusion pump and target chamber to be roughed to the purge pressure of $\sim 0.1$ mbar. The butterfly valve was then closed and the cryotrap methanol recirculator/chiller started. It took about four hours for the cryobaffle to reach its ultimate temperature of $-75^{\circ} \mathrm{C}$. The diffusion pump power was then turned on. When its vapor jets were established, the butterfly valve was slowly opened. The target ionization gauge could be turned on (pressure $<2 \times 10^{-4}$ mbar) within $15 \mathrm{~s}$ after the valve was fully open, indicating that the time for passage through the transition region was less than this.

To turn the system off when venting the target to air, the high-vacuum valve was closed and the diffusion pump turned off. When it was cool, the cryotrap was warmed while the pump body was maintained at foreline purge pressure. If a long down time was anticipated, the foreline was vented with desiccated air up to atmospheric pressure. A variation on this procedure has been recommended by several

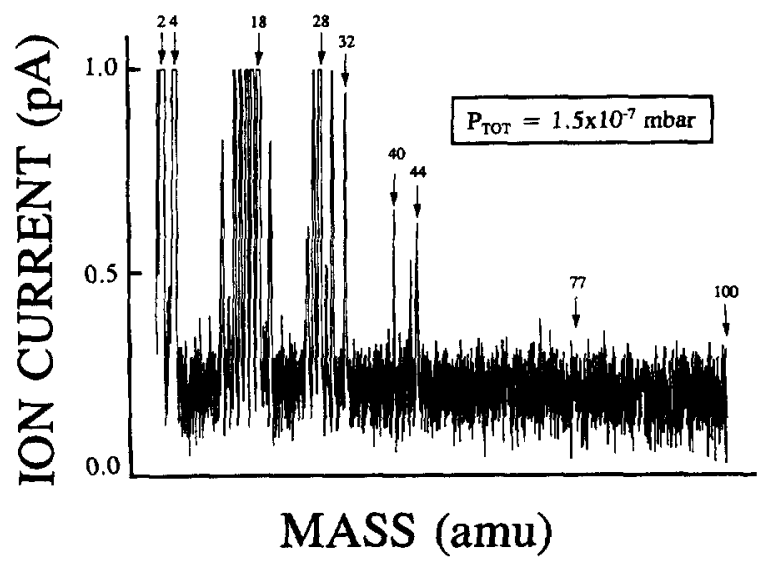

FIG. 5. Mass scan of target chamber (see the text).

authors. ${ }^{7,13,17}$ When the system is being shut down, they suggest turning off the diffusion pump and warming up the cryotrap under a target chamber purge with the high-vacuum valve open. This would reduce evaporation into the target chamber of trapped hydrocarbons from the cryotrap as it is warmed, and would also eliminate backstreaming bursts as the diffusion pump jets shut down. We have the capability to purge from our target chamber, but have not tried this to date. The target chamber has a valved port which permits its evacuation by an external liquid nitrogen sorption pump. This allows us to rough the target to pressures lower than the foreline purge pressure of $0.1 \mathrm{mbar}$ if we desire. It also permits us to leave the diffusion pump on when access to the inside of the target chamber is required.

In order to minimize outgassing of the Viton seals in our system (these are the butterfly seal, the butterfly shaft seals, the two diffusion pump/chamber connecting seals, and the seal on the valve leading to the external sorption pump) we lightly coated them with Santovac-5..$^{22,28}$ Aside from our temporary use of diffusion pump oil in the forepump, we have not followed any other exotic procedures, such as prebaking pumping fluids or o-rings.

\section{RESULTS AND DISCUSSION}

The vacuum system described in this article has proven to work very well in the application for which it was designed: the provision of high-throughput noble-gas pumping in close proximity to a chamber requiring "UHV surface physics" conditions. The ultimate evidence for this is that we have observed no change in the performance of the polarized electron source subsequent to the vacuum system's installation. To document more quantitatively any contamination introduced by the diffusion pump/foreline pumping system, we have routinely made mass scans of our target and electron source chambers using quadrupole mass analyzers (Leybold Heraus Qaudruvac Q100 and Spectramass 100A, respectively) with Faraday-cup ion detectors. Both of these devices had mass ranges between 2 and 100 amu. (The quadrupole head in the target was located at the end of the chamber nearest the polarized electron source; see Fig. 1.) 


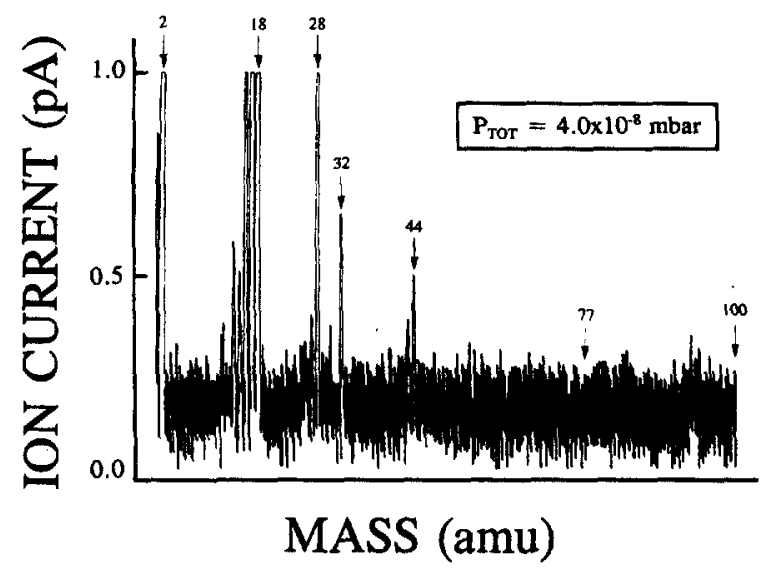

FIG. 6. Mass scan of target chamber (see the text).

Figures 5-7 are mass scans made of the target chamber after its initial pumpdown under the following conditions. Figure 5: The chamber was roughed out with a sorption pump and baked for two weeks at a reasonably uniform $\left( \pm 15^{\circ} \mathrm{C}\right.$ ) temperature of $\sim 130^{\circ} \mathrm{C}$. It was pumped by a 120 $\ell / \mathrm{s}$ noble-gas diode ion pump (Perkin Elmer DI). The scan of Fig. 5 was taken at the end of this period. This scan indicates a system relatively free of organic contaminants, with residual peaks due to cleaning solvents (acetone, mass 43; methanol, masses 13-16), and the acetylene soot used to suppress light reffection (possible partial peaks at masses 26-30). Note the absence of any peaks characteristic of Santovac-5 cracking (masses $51,57,63,64,65,77,78)^{32}$ or forepump oil (e.g., 39, 41, 42, low 50s). ${ }^{14,19}$ Figures 5-7 were all taken on the most sensitive range for detected current: $10^{-13} \mathrm{~A}$. Thus their full vertical scale corresponds to an upper limit of roughly $10^{-8} \mathrm{mbar}$ partial pressure for organic molecules and their framents. ${ }^{33}$ Figure 6: This scan was taken immediately after the target chamber had been opened to both diffusion pumps for the first time. Note the immediate drop by a factor of $\sim 3$ in the total pressure due to the increase by over an order of magnitude in pumping speed, and the attendant drop in all of the partial pressures with the possible exception of $\mathrm{CO}_{2}$ (mass 44). In these first tests,

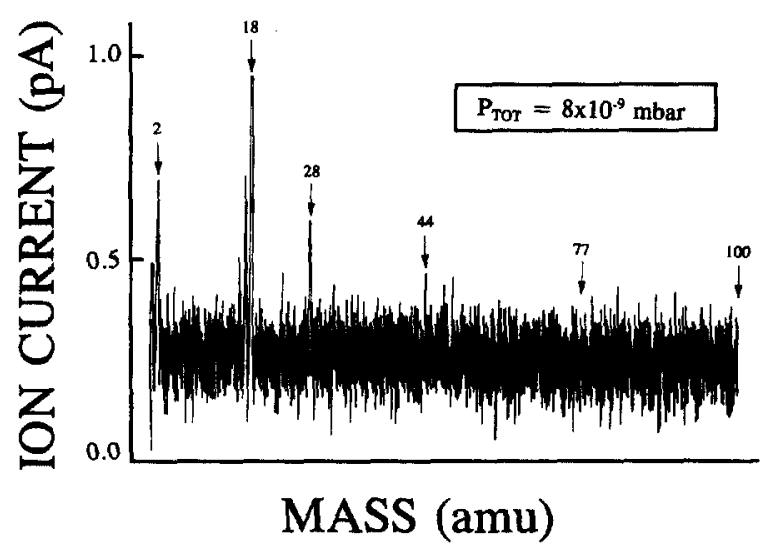

Fig. 7. Mass scan of target chamber (see the text). liquid nitrogen was used to cool the cryotraps, as opposed to $-75^{\circ} \mathrm{C}$ methanol. Figure 7: After one week of pumping, the total chamber pressure had fallen to $8 \times 10^{-9}$ mbar. The only observable mass peaks are due to $\mathrm{H}_{2}, \mathrm{H}_{2} \mathrm{O}, \mathrm{N}_{2}$ (and perhaps $\mathrm{CO}$ ), and $\mathrm{O}_{2}$. Partial pressures of organic fractions and $\mathrm{CO}_{2}$ are not detectable. It is our belief that the ultimate pressure of this system is limited primarily by the lack of UHV engineering and practice in its construction. While all parts were carefully cleaned and handled with polyethylene gloves during assembly, no measures were taken to eliminate virtual leaks, teflon tubes were used as electrical wire insulators, and acetylene soot was used liberally for light reduction. UHV systems with no Viton using untrapped single-structure diffusion pumps have reached pressures below $5 \times 10^{-10}$ mbar. $^{22}$

After these scans were made, the cryotraps were switched to methanol coolant. No change was observed in the residual gas analyzer (RGA) scans we recorded. Since the initial pumpdown more than three years ago, the system has operated more-or-less continuously, with no effect on the polarized electron source performance, and with no detectable partial pressure of hydrocarbon contaminants directly relatable to forepump oil or Santovac-5, either in the target or electron source.

A number of reports have noted the relative insensitivity of RGA analysis compared with techniques such as electron spectroscopy for chemical analysis (ESCA) and low-energy electron diffraction (LEED), and the potential difficulties associated with inferring hydrocarbon contamination from RGA spectra. ${ }^{9,14,19,34}$ We found that the target RGA was very sensitive to trace amounts of oxygen and cesium admitted to the electron source chamber, "two valves away." We were, however, initially concerned about the lack of any observable peak at mass 77, thinking that this might be the result of poor detection efficiency for trace hydrocarbon contamination. This concern was at least partially eliminated, however, following a singular vacuum disaster which occurred when the interlock system was intentionally turned off momentarily to check an electrical connection. At just this point, the foreline for the large pump was accidentally vented to atmosphere with all foreline and high vacuum valves fully open. This resulted in visible oil deposits in the target chamber, although none were apparent on the RGA head. More severe contamination was probably prevented by the mechanical blockage afforded by the diffusion pump cryoplate. As soon as the vacuum system could be restarted, a target mass scan was taken indicating, among a forest of hydrocarbon peaks, a mass 77 partial pressure of $5 \times 10^{-7}$ mbar.

We have seen no evidence in normal operation for light hydrocarbon fractions typical of forepump oil. As mentioned earlier, these fractions are observed even with fully fractionating diffusion pumps when forelines are not trapped or purged. We take this as evidence for the cleanliness of our forelines. No peaks due to organic outgassing from the Viton were observed either. Ultimately, the cleanliness of our system has been demonstrated pragmatically; no deleterious effects on the GaAs source operation have been observed due to use of the diffusion pumps and forelines. 
Over the course of three years of operation, operator error and unreliable sealing by the high-vacuum butterfly valves have led us on several occasions to remove the diffusion pumps from the system for inspection and/or repair. At these times we cleaned the cryoplates, although only once, in the catastrophic incident mentioned above, was there visible evidence of oil accumulation on the pump walls or trap surface. We have thus effected unintentional quasi-periodic cryotrap "regeneration," which has certainly helped reduce longterm contaminant accumulation.

We draw from our experience the following conclusions:

(1) Systems such as our polarized electron source, which is typical of UHV surface science installations, can have at least peripheral pumping provided by diffusion pumps, without resort to exotic liquid nitrogen trapping schemes. Moreover, our experience has led us to believe that direct pumping of such chambers by $-75^{\circ} \mathrm{C}$ cryotrapped integral diffusion pumping systems would work. Cleanliness of the foreline in either type of installation would be crucial.

(2) Of all the measures we took to ensure clean pumping, beyond the use of cryotrapped single-structure diffusion pumps, we believe that prevention of foreline contamination is the most important. This is easily and effectively accomplished by traps and a nitrogen purge. In addition, long forelines consistent with system throughput requirements provide an auxillary measure of isolation. Use of diffusion pump oil in the forepump is of dubious value.

(3) Diffusion pump trapping at $-75^{\circ} \mathrm{C}$, as opposed to liquid nitrogen temperature, is certainly sufficient to eliminate backstreaming contamination in systems like ours. It is possible that the use of $-30^{\circ} \mathrm{C}$ Freon or even chilled water would be adequate.

(4) A good interlock is essential to avoid vacuum disasters. While the intelligence and flexibility of a computerbased interlock might be necessary for an extensive vacuum system, a basic relay interlock may be more attractive for a smaller system in terms of simplicity, cost, and ease of use.

\section{ACKNOWLEDGMENTS}

The authors would like to thank D. Crutcher, C. McWhorter, and T. Deskin for assistance in construction of the vacuum system. M. Hablanian of Varian Associates and Ken Pacioni of Edwards High Vacuum Ltd. gave us much useful advice. This work was supported by the Physics Division of the National Science Foundation and the University of Missouri.

${ }^{1}$ J. E. Furst, W. M. K. P. Wijayaratna, D. H. Madison, and T. J. Gay, Phys. Rev. A 47, 3775 (1993).

${ }^{2}$ T. J. Gay, M. A. Khakoo, J. A. Brand, J. E. Furst, W. V. Meyer, and W. M. K. P. Wijayaratna, Rev. Sci. Instrum. 63, 114 (1992).

${ }^{3}$ E. L. Garwin, R. E. Kirby, C. K. Sinclair, and A. Roder, SLAC pub. 2715 (March 1981).

${ }^{4}$ X. Q. Guo, D. M. Crowe, M. S. Lubell, F. -C. Tang, A. Vasilakis, M. Eminyan, and J. Slevin, Rev. Sci. Instrum. 61, 1858 (1990).

${ }^{5}$ J. F. O'Hanlon, A User's Guide to Vacuum Technology (Wiley, New York, 1980).

${ }^{6}$ Vacuum Physics and Technology, Methods of Experimental Physics Vol. 14, edited by G. L. Weissler and R. W. Carlson, series editors, L. Marton and C. Marton (Academic, New York, 1979).

${ }^{7}$ D. W. Jones and C. A. Tsonis, J. Vac. Sci. Technol. 1, 19 (1964).

${ }^{8}$ T. W. Haas and A. G. Jackson, J. Vac. Sci. Technol. 3, 168 (1966).

${ }^{9}$ R. D. Gretz, J. Vac. Sci. Technol. 5, 49 (1967).

${ }^{10}$ M. H. Hablanian, J. Vac. Sci. Technol. 6, 265 (1967).

${ }^{11}$ P. M. Danielson and F. C. Mrazek, J. Vac. Sci. Technol. 6, 423 (1967).

${ }^{12} \mathrm{~L}$. Holland, Vacuum 21, 45 (1971).

${ }^{13}$ D. J. Santeler, J. Vac. Sci. Technol. 8, 299 (1971).

${ }^{14}$ M. H. Hablanian and J. C. Maliakal, J. Vac. Sci. Technol. 10, 58 (1973).

${ }^{15} \mathrm{G}$. Rettinghaus and W. K. Huber, Vacuum 24, 249 (1974).

${ }^{16} \mathrm{P}$. R. Forant and M. Hablanian, Varian Vacuum technical bulletin, VR134

${ }^{17}$ D. M. Hoffman, J. Vac. Sci. Technol. 16, 71 (1979).

${ }^{18}$ N. T. M. Dennis, B. H. Colwell, L. Laurenson, and J. R. H. Newton, Vacuum 28, 551 (1978).

${ }^{19}$ L. Maurice, P. Duval, and G. Gorinas, J. Vac. Sci. Technol. 16, 741 (1979).

${ }^{20}$ N. S. Harris, Vacuum 30, 175 (1980).

${ }^{21}$ M. H. Hablanian, J. Vac. Sci. Technol. 18, 1156 (1981).

${ }^{22}$ N. T. M. Dennis, L. Laurenson, A. Devaney, and B. H. Colwell, J. Vac. Sci. Technol. 20, 996 (1982).

${ }^{23}$ N. Yoshimura, H. Hirano, S. Norioka, and T. Etoh, J. Vac. Sci. Technol. A 2, 61 (1984).

${ }^{24}$ G. Lewin, J. Vac. Sci. Technol. A 3, 2212 (1985).

${ }^{25}$ M. H. Hablanian, J. Vac. Sci. Technol. A 4, 286 (1986).

${ }^{26}$ L. H. Dubois, J. Vac. Sci. Technol. A 6, 162 (1988).

${ }^{27}$ Monsanto Chemical Company Publication IC/FP-213B.

${ }^{28}$ D. Power, N. T. M. Dennis, R. D. Oswald, and B. H. Colwell, Vacuum 24, 117 (1974).

${ }^{29} \mathrm{M}$. D. Andonian, Andonian Cryogenics Inc. (private communication).

${ }^{30}$ Product of Kurt J. Lesker Co.

${ }^{31}$ Product of Welch Vacuum Technology Inc.

${ }^{32}$ E. D'Anna, G. Leggieri, A. Luches, and A. Perrone, J. Vac. Sci. Technol. A 5, 3436 (1987).

${ }^{33}$ Operating instruction manual, Leybold-Heraeus Quadruvac Q100 (\#GA752, 184).

${ }^{34}$ Vacuum Generator's Ltd. technical bulletin 2-06-1: UHV Pumps-A Comparison of Performance. 